\title{
Presença de DNA da Leishmania (V.) braziliensis na Mucosa Nasal Clinicamente Saudável em Pacientes com Leishmaniose Cutânea*
}

\author{
Presence of Parasite DNA in Clinically Unaffected Nasal \\ Mucosa During Cutaneous Leishmaniasis Caused by \\ Leishmania ( $V$.) braziliensis
}

\begin{abstract}
Amanda Canário ${ }^{1,2,3}$, Michelle Queiroz ${ }^{3}$, Gustavo Barreto ${ }^{3}$; Thiago Cavalcante ${ }^{3}$; Vanessa $^{2}$ Riesz $^{1}$; Rohit Sharma ${ }^{1}$; Almério de Noronha ${ }^{1}$; Thaizza Correia ${ }^{1}$; Manoel Barral-Netto ${ }^{1,2}$; Aldina Barral $^{1,2}$; Ricardo Khouri ${ }^{1,2}$; Viviane Boaventura ${ }^{1,2,3}$.

${ }^{1}$ Instituto Gonçalo Moniz (CPqGM) - Fundação Oswaldo Cruz (Fiocruz) Bahia; ${ }^{2}$ Programa de Pós-Graduação em Ciências da Saúde (PPgCS) - Universidade Federal da Bahia (UFBA); ${ }^{3}$ Serviço de Otorrinolaringologia do Hospital Santa Izabel/Santa Casa de Misericórdia da Bahia (HSI/SCMBA); Salvador, Bahia, Brazil
\end{abstract}

Correspondence addresses: Dra. Viviane Boaventura vsboaventura@gmail.com

Received: January 30, 2019

Revised: February 20, 2019

Accepted: February 27, 2019

Published: March 27, 2019

Data Availability Statement: All relevant data are within the paper and its Supporting Information files.

Competing interests: The authors have declared that no competing interests exist.

Copyright

(C) 2019 by Santa Casa de Misericórdia da Bahia.

All rights reserved.

ISSN: 2526-5563
Considerando que a lesão da mucosa ocorre tardiamente após a infecção por leishmaniose cutanea (LC), avaliamos se pacientes com doença cutânea por $L$. $V$. braziliensi sem atividade podem carrear DNA do parasita na mucosa nasal aparentemente sadia. Realizamos um estudo de corte transversal, com exame otorrinolaringológico de todos os casos de LC (n-153) atendidos em uma área endêmica na Bahia- Brasil, em um período de 2 anos. Amostras de swab nasal foram coletadas antes do tratamento para avaliação de DNA do parasita. Após 3 meses, esses indivíduos foram reavaliados para identificar o status da doença. $\mathrm{O}$ DNA do parasita foi detectado em 7,8\% (12/153) de pacientes com LC sem lesão aparente em mucosa nasal. $O$ DNA estava presente em pacientes com fatores de risco conhecidos para desenvolvimento de lesão de mucosa, como lesões cutâneas em maior número (mediana de 1,5 vs $1,0, p=0,044$ ) e maiores (mediana 2,7 vs $1,6 \mathrm{~cm}, \mathrm{p}=\mathbf{0 , 0 1 3}$ ). Além disso, esses indivíduos com parasita na mucosa evoluíram mais frequentemente para formas atípicas da $\mathrm{LC}[45,5 \%$ vs $11,5 \%$; $=0,009]$, e necessitaram de mais ciclos de tratamento para atingir a cura clínica da lesão cutânea (mediana de 2 vs $1, \mathbf{p}<0,05$ ). Os resultados sugerem tropismo precoce do parasita para a mucosa nasal e um fenótipo clínico dos casos de LC com DNA de parasita detectável na mucosa. Estudos futuros poderão avaliar se a presença do parasita na mucosa servirá como marcador prognóstico de risco de desenvolver leishmaniose mucocutânea.

Palavras-chave: Leishmania braziliensis; Leishmaniose em mucosa; Swab nasal; Reação em cadeia da polimerase.

We aimed to detect Leishmania DNA carriage in nasal mucosa of individuals with cutaneous leishmaniasis (CL) caused by Leishmania (Viannia) braziliensis. A crosssectional study was performed in all individuals with CL without nasal lesions $(\mathrm{n}=153)$ attended within 2 years in an endemic area of $L$. (Viannia) braziliensis in Bahia (Brazil).

Publicado na revista Journal of Microbiology and Infection, em Janeiro de 2019. Canário A, et al. Clin Microbiol Infect. 2019 Jan 4. pii: S1 198-743X(18)30838-3. Doi: 10.1016/j.cmi.2018.12.027. 
An otorhinolaryngologist assessed the clinical status of the nasal mucosa by anterior rhinoscopy and endoscopic examinations. Swab samples were collected for parasite DNA detection by PCR from all individuals before standard treatment for leishmaniasis. A second evaluation 3 months after treatment was performed to assess clinical outcomes.Parasite DNA was detected in 7.8\% (12/153) of clinically healthy nasal mucosa of individuals with CL. Interestingly, DNA was more frequently identified in individuals with more skin lesions (median 1.5, interquartile range (IQR) 1-3.5 versus 1.0, IQR 1-1.5; p 0.044), or larger injuries (median 2.7, IQR 2-3.8 versus 1.6, IQR 1-2.5; p 0.013). Additionally, the disease of those individuals with positive PCR evolved more frequently to unusual forms of leishmaniasis (recidiva cutis and disseminated) $(45.5 \%(5 / 11)$ versus $11.5 \%(14 / 122)$; p 0.009), and required more cycles of treatment to reach clinical cure (median 2, IQR 1-4 versus 1 , IQR 1-2; p 0.05). These findings suggest an early parasite tropism to nasal mucosa in L. (Viannia) braziliensis infection and a clinical phenotype of CL cases associated with parasite DNA in nasal mucosa. Future studies should evaluate whether PCR of nasal swab samples could serve as a prognostic tool for individuals at risk of mucocutaneous leishmaniasis.

Keywords: Cutaneous leishmaniasis; Leishmania braziliensis; Mucosal leishmaniasis; Nasal swab; Polymerase chain reaction.

\section{Introdução}

A leishmaniose tegumentar (LT) representa um amplo espectro de formas clínicas da doença, entre elas, as leishmanioses cutânea (LC), a mucocutanea (LMC), a disseminada (LD) e a recidiva cutis (LRC). A forma cutânea é a mais frequente e pode, posteriormente (em média 3 anos), envolver a mucosa, causando deformidade facial, com lesões destrutivas e mutilantes principalmente na porção anterior da mucosa nasal. ${ }^{1}$ Esse envolvimento da mucosa costuma ocorrer em cerca de $4 \%$ dos pacientes com histórico de LC. Assim, nosso objetivo foi avaliar se a Leishmania pode ser detectável, por métodos moleculares, em pacientes com LC causada por $L$. (V.) braziliensis, a única espécie que circula na Bahia. ${ }^{2}$

\section{Material e Métodos}

Entre fevereiro de 2015 e novembro de 2017, foi realizado um estudo de corte transversal em um centro de referencia para LT, na área endêmica do Vale do Jiquiriça, na Bahia/Brasil. Exame clínico e otorrinolaringológico, teste cutâneo de Montenegro e biópsia da lesão cutânea foram realizados em todos os 153 casos de LC atendidos no período.

O diagnóstico de $\mathrm{LC}$ foi baseado na presença de lesão cutânea ulcerada, indolor, bem circunscrita, com bordas eritematosas elevadas ${ }^{3}$ e positividade no teste cutâneo (presente em 84\%) e/ou parasita detectável no exame histopatológico da lesão cutânea (43\%).

Antes do exame otorrinolaringológico com espéculo nasal, amostras de swab nasal foram coletadas do septo anterior e corneto inferior de ambas fossas nasais e imediatamente armazenadas em gelo seco para transporte. O processamento para extração de DNA e PCR foi realizado no Laboratório de Enfermidades Infecciosas Transmitidas por Vetores (LEITV), na Fundação Oswaldo Cruz (Fiocruz-Bahia). A condição clínica do paciente após 3 meses do tratamento com antimônio pentavalente (15mg/Kg/dia por 20 dias) foi avaliada para identificar a evolução para LD (mais de 10 lesões localizadas em pelo menos dois segmentos do corpo) ou LRC (pápulas e vesículas na borda da cicatriz cutânea).

A extração de DNA for realizada com kit PureLink Genomic DNA (Invitrogen ${ }^{\circledR}$, California, USA), de acordo com instruções do fabricante, e a presença de DNA de Leishmania DNA foi avaliado por PCR seguindo protocolo adaptado por Oliveira e colaboradores ${ }^{4}$. Os resultados foram descritos em mediana e intervalo interquartil(IIQ) e teste de Fisher ou Mann-Whitney foram realizados usando SPSS software (version 20.0, IBM, Chicago, USA).

\section{Resultados}

O DNA de leishmania foi detectado na mucosa aparentemente sadia de 12 dos 153 (7,8\%) pacientes com LC (Tabela 1). Casos PCR positivos apresentaram mais lesão $(1,5 v s 1,0 ; p=0,044)$ e de tamanho maior $(2,75 v s 1,6 ; \mathrm{p}=0,013)$ comparado a casos com PCR negativo. Após 3 meses do tratamento, os casos PCR positivos apresentaram mais frequentemente formas atípicas da LT [45,5\% (5/11) vs 11,5\% (14/122), $\mathrm{p}=0,009]$. Dos 11 casos 
PCR positivos que realizaram a valiação clínica póstratamento, $4(36,4 \%)$ evoluíram para LRC e 1 $(9,1 \%)$ para LD. Adicionalmente, os casos PCR positivos necessitaram de mais série de tratamento para atingir a cura (2 vs 1; $\mathrm{p}=0,031)$. Não observados aparecimento de lesão mucosa em nenhum dos 153 casos.

\section{Discussão}

A condição de carreador de DNA de Leishmania na mucosa aparentemente sadia foi detectada em $7,8 \%$ dos casos de LC e esses indivíduos apresentaram tanto evolução clínica como resposta terapêutica diferente do observado nos casos PCR negativos. Dados publicados recentemente na Colômbia mostraram maior frequência de DNA do parasita (45-61,5\%) na mucosa não afetada clinicamente em pacientes com LC. ${ }^{5,6}$ Acreditamos que a discrepância seja resultado de variação no tropismo das diferentes subespécies de Leishmania (Vianna) que circulam na Colômbia. A Leishmania panamensis, por exemplo, causa mais frequentemente doença cutânea e mucosa concomitante. ${ }^{7}$ Outra possibilidade é que a presença de um vírus RNA infectando espécies de leishmania circulantes na Colômbia esteja associado com aumento do risco de lesão mucosa subsequente. ${ }^{8-11}$ Na Bahia, onde apenas a L. (V.) braziliensis circula, ${ }^{2}$ esse vírus não foi detectado (dados não apresentados, Aldina Barral, 2001), o que pode contribuir para a menor frequência de LM observada nessa região.

A presença de DNA de parasita detectável na mucosa não necessariamente significa metástase de lesão cutânea ou replicação do parasita nesse sítio. Entretanto, é improvável que represente infecção direta da mucosa pela picada do inseto vetor. Devese destacar que vários estudos têm demostrado amastigota de Leishmania na lesão mucosa no exame histopatológico, sugerindo que o parasita pode se estabelecer e reproduzem-se na mucosa nasal. ${ }^{9}$

Verificamos que fatores previamente reconhecidos como de risco para desenvolver LM estavam presentes nos pacientes com PCR positivo, ${ }^{1,3}$ incluindo lesões múltiplas e maiores. Adicionalmente, o estado de portador do DNA da Leishmania na mucosa nasal

Tabela 1. Características de LC em pacientes com PCR positivo e negativo.

\begin{tabular}{|c|c|c|c|}
\hline & \multicolumn{2}{|c|}{ PCR } & \multirow[b]{2}{*}{$\mathbf{p}^{\mathbf{a}}$} \\
\hline & $\begin{array}{c}\text { Positivo } \\
12(7,8 \%)\end{array}$ & $\begin{array}{l}\text { Negativo } \\
141(92,3)\end{array}$ & \\
\hline Sexo-masculino: $\mathrm{n}(\%)$ & $9(75 \%)$ & $79(56 \%)$ & 0,239 \\
\hline Idade - anos: média (IQR)* & $47(22 ; 54)$ & $36(25,5 ; 49)$ & 0,724 \\
\hline \multicolumn{4}{|l|}{ Lesão cutânea } \\
\hline Número: média(IQR) & $1,5(1 ; 3,5)$ & $1(1 ; 1,5)$ & 0,044 \\
\hline Tamanho (cm): média(IQR) & $2,75(2 ; 3,8)$ & $1,6(1 ; 2,5)$ & 0,013 \\
\hline Local acima do contorno: $\mathrm{n}(5 \%)$ & $6(50 \%)$ & $51(36,2 \%)$ & 0,365 \\
\hline Duração dos sintomas (meses): média(IQR) & $2(1 ; 2,75)$ & $2(1 ; 3)$ & 0,863 \\
\hline $\mathrm{LST}^{*}(\mathrm{~mm}):$ média (IQR) & $11,5(4 ; 18)$ & $15(10 ; 20)$ & 0,277 \\
\hline Tratamento com MA* - número de ciclos: média (IQR) & $2(1 ; 4)$ & $1(1 ; 2)$ & 0,031 \\
\hline Seguimento até a cura clínica (1,5 a 7 meses): n (\%) & $11(91,7 \%)$ & $122(86,5 \%)$ & 0,516 \\
\hline \multicolumn{4}{|l|}{ Resultado } \\
\hline Recidiva cutis: $\mathrm{n}(\%)$ & $4(36,4 \%)$ & $11(9 \%)$ & 0,022 \\
\hline Leishmania disseminada: $\mathrm{n}(\%)$ & $1(9,1 \%)$ & $3(2,5 \%)$ & 0,295 \\
\hline Cura clínica/cicatrização completa: $\mathrm{n}(\%)$ & $6(54,5 \%)$ & $82(67,2 \%)$ & 0,295 \\
\hline
\end{tabular}

a - Fisher (categorias variáveis) ou Mann-Whitney test (variáveis numéricas); *IQR - interquartil rate; LST - Leishmania test; MA - meglumine antimoniate.*Tabela extraída e traduzida do artigo original: Canário A, et al. Clin Microbiol Infect. 2019 Jan 4. pii: S1198-743X(18)30838-3. Doi: 10.1016/j.cmi.2018.12.027. 
esteve associado à evolução para formas atípicas $(45,5 \%$ vs $11,5 \%)$. Sabe-se que a prevalência de envolvimento da mucosa em pacientes com LD é maior que na LC. ${ }^{10}$ Assim, a condição de carreador do DNA do parasita na mucosa pode estar associada ao desenvolvimento subsequente de LMC.

Não podemos avaliar o impacto do tratamento na eliminação desse estado de carreador pois não foram recoletadas novas amostras no momento da reavaliação. Entretanto, considerando que o tratamento precoce da LC é um fator de sucesso na evolução clínica, um acompanhamento rotineiro com coleta de swab e PCR poderia ser testado como ferramenta de screening para LMC. Adicionalmente, não podemos predizer o risco de desenvolver LMC já que essa forma clínica pode surgir muitos anos após a cura da LC, o que necessitaria de um acompanhamento a longo prazo.

Assim, o estado de portador de DNA do parasita na mucosa de casos de LC está associado à presença de apresentação clínica e evolução mais severa da doença. Estudos prospectivos deverão ser realizados para avaliar se a presença de DNA do parasita na mucosa nasal de pacientes com L. braziliensis pode ser um fator de risco para LMC. Esse estudo recebeu financiamento da FAPESB (SUS0024/2013) e da Coordenação de Aperfeiçoamento de Pessoal de Nível Superior - Brasil (CAPES) - Finance Code 001.

\section{Referências}

1 Marsden PD, Llanos-Cuentas EA, Lago EL, Cuba CC, Barreto AC, Costa JM, et al. Human mucocutaneous leishmaniasis in Três Braços, Bahia - Brazil. An area of Leishmania braziliensis braziliensis transmission. III. Mucosal disease presentation and initial evolution. Rev Soc Bras Med Trop. 1984;17:179-86.doi:10.1590/S0037-86821984000400003.
2. Rosa A, Cuba C, Vexenat A, Barreto A, Marsden P. Predominance of Leishmania braziliensis braziliensis in the regions of Tres Brac'os and Corte de Pedra, Bahia, Brazil. Trans R Soc Trop Med Hyg. 1988;82:409-10.

3. Jones TC, Johnson WD, Barretto AC, Lago E, Badaro R, Cerf B, et al. Epidemiology of American cutaneous leishmaniasis due to Leishmania braziliensis braziliensis. J Infect Dis. 1987;156:73-83.

4. Oliveira JGS, Novais FO, De Oliveira CI, Da Cruz AC, Campos LF, Da Rocha A V., et al. Polymerase chain reaction (PCR) is highly sensitive for diagnosis of mucosal leishmaniasis. Acta Trop. 2005;94:55-9. doi:10.1016/j.actatropica.2004.12.003.

5. Figueroa R, Lozano L, Romero I, Cardona M, Prager $\mathrm{M}$, Pacheco R, et al. Detection of Leishmania in unaffected mucosal tissues of patients with cutaneous leishmaniasis caused by Leishmania (Viannia) species. J Infect Dis. 2009;200:638-46. doi:10.1086/ 600109.

6. Martínez-Valencia AJ, Daza-Rivera CF, Rosales-Chilama M, Cossio A, Casadiego Rincón EJ, Desai MM, et al. Clinical and parasitological factors in parasite persistence after treatment and clinical cure of cutaneous leishmaniasis. PLoS Negl Trop Dis. 2017;11:115. doi:10.1371/journal.pntd.0005713.

7. Osorio LE, Castillo CM, Ochoa MT. Mucosal leishmaniasis due to Leishmania (Viannia) panamensis in Colombia: clinical characteristics. Am J Trop Med Hyg. 1998;59:49-52.

8. Zangger H, Ronet C, Desponds C, Kuhlmann FM, Robinson J, Hartley MA, et al. Detection of Leishmania RNA Virus in Leishmania Parasites. PLoS Negl Trop Dis. 2013;7:1-11. doi:10.1371/journal.pntd.0002006.

9. Boaventura VS, Cafe V, Costa J, Oliveira F, Bafica A, Rosato A, et al. Short report: Concomitant early mucosal and cutaneous leishmaniasis in Brazil. Am J Trop Med Hyg. 2006;75:267-9.

10. Jirmanus L, Glesby MJ, GuimaratPes LH, Lago E, Rosa ME, Machado PR, et al. Epidemiological and clinical changes in American tegumentary leishmaniasis in an area of Leishmania (Viannia) braziliensis transmission over a 20-year period. Am J Trop Med Hyg. 2012;86:42633. doi:10.4269/ajtmh.2012.11-0378. 